\title{
MODEL PEMBELAJARAN COOPERATIVE INTEGRATED READING AND COMPOSITION (CIRC) UNTUK MENINGKATKAN KEMAMPUAN SOSIAL MAHASISWA
}

\author{
Ayu Faiza Algifahmy 1) * \\ ${ }^{1}$ Universitas Islam Negeri Walisongo Semarang \\ *E-mail: ayufaiza@walisongo.ac.id
}

\begin{abstract}
The CIRC (Cooperative Integrated Reading and Composition) learning model is a comprehensive learning program to teach reading and writing to students used in each course in the History of Islamic Civilization. This study aims to determine the effect of the CIRC learning model oflearning outcomes of cognitive aspects of students in the History of Islamic Civilization course at the Faculty of Da'wah and Communication. This research is an experimental research. The population in this study are students of the History of Islamic Civilization course, so it can be concluded that the average group learning outcomes will be better. The purpose of this study is to describe the application of the CIRC method in improving students' social abilities and describing their improvement. Based on these results, it can be concluded that the application of the CIRC method can improve social skills and read students' understanding.
\end{abstract}

Keywords: CIRC Method, Social Ability, Student

\begin{abstract}
Abstrak
Model pembelajaran CIRC (Cooperative Integrated Reading and Composition) merupakan program pembelajaran komprehensif untuk mengajarkan membaca dan menulis pada mahasiswa digunakan pada setiap mata kuliah Sejarah Peradaban Islam. Penelitian ini bertujuan untuk mengetahui pengaruh model pembelajaran CIRC hasil belajar aspek kognitif mahasiswa pada mata kuliah Sejarah Peradaban Islam di Fakultas Dakwah dan Komunikasi. Penelitian ini adalah penelitian eksperimen. Populasi dalam penelitian ini adalah mahasiswa mata kuliah Sejarah Peradaban Islam, maka dapat disimpulkan bahwa rata-rata hasil belajar kelompok akan lebih baik. Tujuan penelitian ini adalah untuk mendeskripsikan penerapan metode CIRC dalam meningkatkan kemampuan sosial mahasiswa serta mendeksripsikan peningkatannya. Berdasarkan hasil tersebut, dapat disimpulkan bahwa penerapan metode CIRC dapat meningkatkan kemampuan sosial dan membaca pemahaman mahasiswa.
\end{abstract}

Kata Kunci: Metode CIRC, Kemampuan Sosial. Mahasiswa

\section{PENDAHULUAN}

UIN Walisongo Semarang sebagai lembaga pendidikan berusaha mewujudkan pelayanan pendidikan yang bermutu bagi masyarakat. Peningkatan dan pelayanan tentang pendidikan sebagai upaya untuk mewujudkan World Class Islamic University di level Asia. Demi mewujudkan visi UIN Walisongo Semarang menuju World Class Islamic University tersebut, penulis mengangkat tema peningkatan pembelajaran mata kuliah Sejarah Peradaban Islam. 
Tulisan ini disusun berdasarkan identifikasi beberapa isu atau problematika yang ditemukan dalam melaksanakan tugas sebagai Dosen (Pendidik) di instansi tempat bekerja, yaitu di Fakultas Dakwah dan komunikasi UIN Walisongo Semarang. Fakultas dakwah dan komunikasi memiliki mahasiswa yang heterogen, di mana mahasiswa datang dari berbagai macam latar belakang suku, ras dan adat istiadat dan background sekolah yang berbeda-beda, sehingga dengan kondisi mahasiswa yang berbeda itu seharusnya dosen dapat membuat pembelajaran yang lebih variatif, dan menyenangkan. Berkaitan dengan gaya belajar visual auditori dan kinestetik, dosen seharusnya dapat memetakan potensi anak didiknya seperti apa. Dengan adanya hal itu, maka dosen seharusnya dapat mendidik sesuai dengan kebutuhan mahasiswa/ peserta didik (Belum optimalnya menerapkan Model Pembelajaran kepada mahasiswa).

Dalam hal ini kemampuan membaca, menulis dan berbicara yang selama ini digadang-gadang sebagai sebuah rujukan untuk memperoleh ilmu pengetahuan menjadi semakin meredup seiring berjalannya waktu. Mahasiswa kini menjadi kurang perduli dengan pentingnya hal tersebut (Muhibbin Syah, 2004: 31-36). Kemudahan dalam mencari informasi dari google dan wikipedia menjadikan mereka kurang berminat untuk belajar lebih jauh. Communication skills secara personal ataupun kelompok juga semakin terkikis. Fenomena saat ini adalah ketika kebanyakan mahasiswa tak lagi mampu untuk menyampaikan argumennya di depan kelas, bisa karena malu, atau karena kurang dalam belajar dan membaca buku (Anwar, 2006: 2023)

\section{METODE}

Jenis penelitian ini adalah field research dengan teknik pengumpulan data berupa observasi, dan pengumpulan dokumen dan sebagainya. Fokus utama dari metode CIRC sebagai cerita dasar adalah membuat penggunaan waktu tindak lanjut menjadi lebih efektif. Para mahasiswa yang bekerja di dalam tim-tim kooperatif dari kegiatankegiatan ini, yang dikoordinasikan dengan pengajaran kelompok membaca, supaya dapat memenuhi tujuan-tujuan dalam bidang lain seperti pemahaman membaca, kosakata, pembacaan pesan, dan ejaan. Para mahasiswa termotivasi untuk saling bekerja satu sama lain dalam kegiatan-kegiatan ini atau rekognisi lainnya yang didasarkan pada pembelajaran seluruh anggota tim. 
Metode kualitatif digunakan untuk menggambarkan suatu kondisi fakta, data, atau objek material yang berupa ungkapan bahasa atau wacana melalui interpretasi yang tepat dan sistematik, Data primer nantinya diperoleh dari hasil angket dan wawancara dengan para siswa yang terlibat langsung dalam penelitian. Sedangkan data sekunder diperoleh dari berbagai literatur baik melalui buku-buku, jurnal-jurnal, maupun studi terdahulu oleh para akademisi yang terkait dengan penelitian ini.

\section{HASIL PENELITIAN DAN PEMBAHASAN}

Di era 4.0 saat ini, perkembangan ilmu pengetahuan dan teknologi sangatlah pesat. Hampir semua data bisa diakses oleh internet. Mahasiswa menjadi sangat candu dengan media sosial, baik itu instagram, youtube, facebook dan twitter. Menjadi tantangan tersendiri ketika setiap orang lebih suka melihat dan membaca informasi lewat android daripada bertemu secara langsung.

Membaca pemahaman merupakan istilah yang digunakan untuk kegiatan membaca yang bertujuan untuk memperoleh informasi yang terkandung dalam teks bacaan. Menurut Tarigan (2008:58) menyatakan bahwa membaca pemahaman (atau reading for understanding) yang dimaksud di sini adalah jenis membaca yang bertujuan untuk memahami standar-standar atau norma-norma kesastraan (literacy standards), resensi kritis (critical review), drama tulis (printed drama), dan pola-pola fiksi (patterns of fiction). Menurut Yunus Abidin (2012: 60) menyatakan bahwa membaca pemahaman dapat pula diartikan sebagai proses sungguh-sungguh yang dilakukan pembaca untuk memperoleh informasi, pesan, dan makna yang terkandung dalam sebuah bacaan.

Berdasarkan beberapa pendapat yang dikemukakan ahli, dalam penelitian ini kemampuan membaca pemahaman adalah kemampuan siswa dalam proses memperoleh informasi dari teks bacaan yang dapat digunakan dalam kehidupan sehari-hari. Anderson 1972: 117 (dalam Somadayo, 2011: 12) menyatakan bahwa membaca pemahaman memiliki tujuan untuk memahami isi bacaan dalam teks. Tujuan tersebut antara lain, (1) Membaca untuk memeroleh rincian-rincian dan fakta-fakta; (2) Membaca untuk mendapatkan ide pokok; (3) Membaca untuk mendapatkan organisasi teks; (4) Membaca untuk mendapatkan kesimpulan; (5) Membaca untuk mendapatkan klasifikasi, dan (6) Membaca untuk membuat perbandingan atau pertentangan. 
Menurut Yunus Abidin, (2016:18), proses pembelajaran membaca secara garis besar harus terdiri atas tiga tahapan yakni tahapan prabaca, tahapan membaca, dan tahapan pascabaca.

Adapun prinsip-prinsip membaca pemahaman Menurut McLaughlin \& Allen, 2002 (dalam Farida, 200: 3), prinsip-prinsip membaca yang di dasarkan pada penelitian yang paling memengaruhi pemahaman membaca ialah seperti yang dikemukakan berikut (1) Pemahaman merupakan proses konstruksi sosial; (2) Keseimbangan kemahiraksaraan adalah kerangka kerja kurikulum yang membantu perkembangan pemahaman; (3) Guru membaca yang profesional (unggul) memengaruhi belajar siswa; (4) Pembaca yang baik memegang peranan yang metodes dan berperan aktif dalam proses membaca;

Selanjutnya (5) Membaca hendaknya terjadi dalam konteks yang bermakna; (6) Siswa menemukan manfaat membaca yang berasal dari berbagai teks pada berbagai tingkatan kelas; (7) Perkembangan kosakata dan pembelajaran memengaruhi pemahaman membaca; (8) Pengikutsertaan adalah suatu faktor kunci pada proses pemahaman; (9) Metode dan keterampilan membaca bisa diajarkan; (10) Asesmen yang dinamis menginformasikan pembelajaran membaca pemahaman. Brown, 1984: 54 (dalam Somadayo, 2011: 16) berpartisipasi aktif dalam proses membaca.

Jenis-jenis membaca pemahaman adalah pemahaman literal, pemahaman interpretasi, pemahaman kritis, dan pemahaman kreatif. Indikator membaca pemahaman dalam penelitian ini adalah membuat prediksi akhir cerita, menuliskan kata-kata sulit dan maknanya, menjawab pertanyaan tentang isi bacaan, serta menceritakan kembali bacaan dengan menggunakan bahasa sendiri. Adapun cara mengungkap data dari indikator-indikator kemampuan membaca pemahaman tersebut adalah melalui tes.

Hasil observasi dan wawancara di lapangan tentang metode diskusi dalam pembelajaran Sejarah Peradaban Islam, sebagai berikut:

1. Penyampaian Dosen

Menyampaikan materi pembelajaran dan penerapan metode membaca dan diskusi, mengajarkan materi yang sesuai standar kompetensi, dibahas dengan metode membaca dan diskusi yang menarik karena mahasiswa mengidentifikasi sebuah bacaan. Pembelajaran dengan metode membaca dan diskusi sangat efektif 
sehingga metode tersebut tepat diterapkan oleh dosen dalam mata kuliah Sejarah Peradaban Islam.

2. Efektivitas mahasiswa

Pengaruh terhadap mahasiswa, mereka menjadi aktif dalam pelaksanaan metode membaca dan diskusi tersebut, dari pengamatan bahwa ketika pelaksanaan pembelajaran dilakukan dengan metode tersebut mahasiswa berani mengemukakan pendapat, bertanya, memberi kesempatan kepada yang lain, bisa memecahkan masalah dan mencatat hasil diskusi dalam kelompok tersebut. Tidak hanya itu mahasiswa merasa senang dengan penggunaan metode CIRC serta menjadi paham dengan materi yang dipelajari dan bisa diterapkan dalam praktik yang dilakukan setelah pembelajaran tersebut. Dengan demikian pelaksanaan metode CIRC sudah sesuai dengan tujuannya yaitu membantu siswa belajar berfikir, mengevaluasi, kesempatan pada mahasiswa lain, memecahkan problem, dan motivasi tinggi (Hisyam Zaini, Bermawy, dan Sekar Ayu Aryani, 2007, 120 121).

Diiskusi ialah suatu proses yang melibatkan dua atau lebih individu yang berintegrasi secara verbal dan saling berhadapan muka mengenai tujuan atau sasaran yang sudah tentu melalui cara tukar menukar informasi, mempertahankan pendapat, atau pemecahan masalah (Binti Maunah, 2009, 131). Menurut Zaini, dkk,metode diskusi memiliki tujuan sebagai berikut dalam membantu siswa (Hisyam Zaini, Bermawy, dan Sekar Ayu Aryani, 2007,120-121).

Tabel 1 Uraian Hasil Kegiatan

Optimalisasi model Pembelajaran Cooperative Integrated Reading and Composition (CIRC)

\begin{tabular}{|l|l|l|}
\hline \multicolumn{2}{|c|}{ Rincian Kegiatan } & \multicolumn{1}{c|}{ Pelaksanaan Kegiatan/ Hasil } \\
\hline a. & Sumber Kegiatan & - \\
\hline b. & Tanggal Pelaksanaan & 2-12 Oktober 2019 \\
\hline c. & Lokasi/ Tempat & $\begin{array}{l}\text { Ruang kelas Fakultas Dakwah dan Komunikasi UIN } \\
\text { Walisongo }\end{array}$ \\
\hline
\end{tabular}




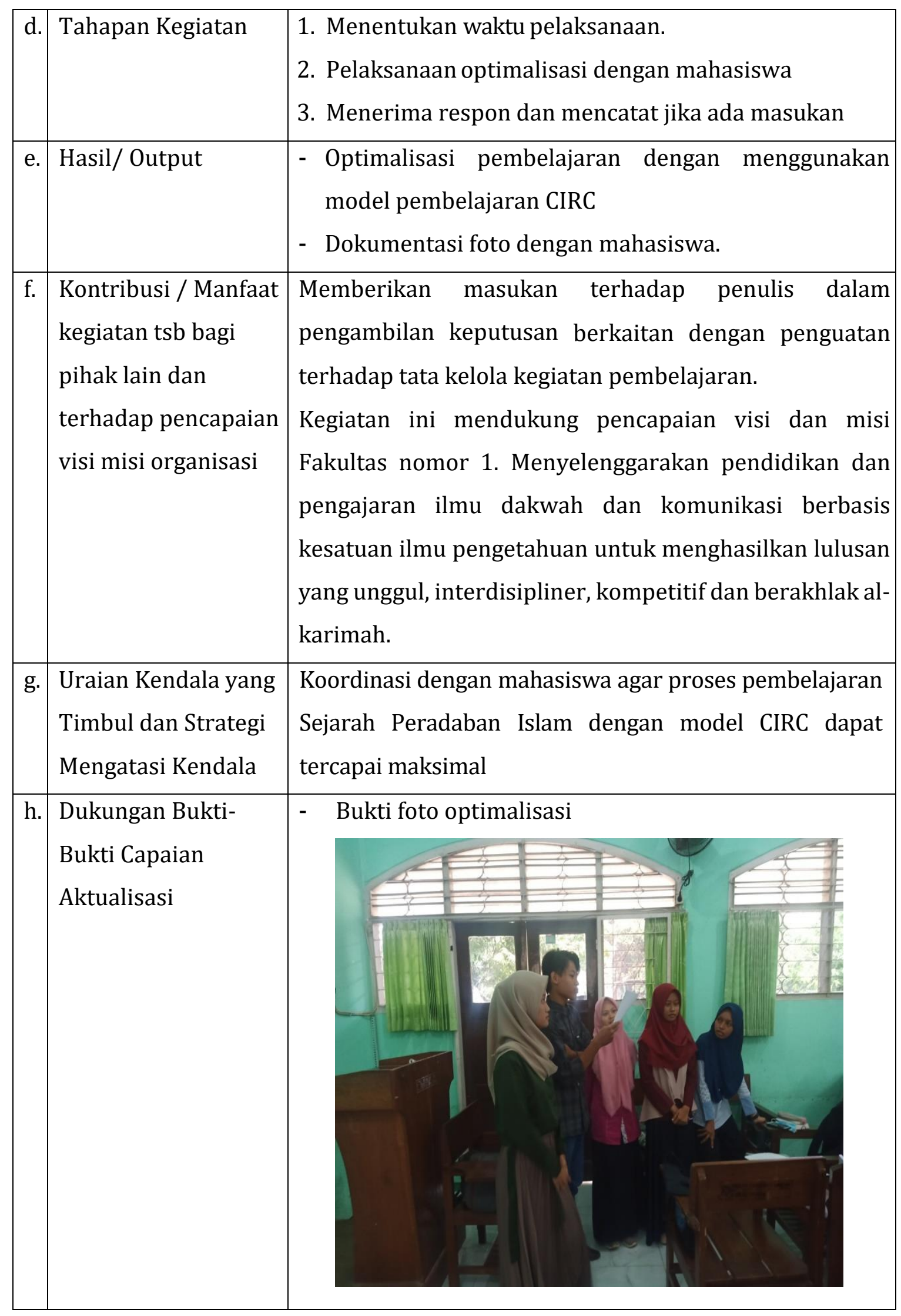


Tabel 2 Uraian Hasil Kegiatan

Pelaksanaan Diskusi

\begin{tabular}{|c|c|c|}
\hline \multicolumn{2}{|r|}{ Rincian Kegiatan } & Pelaksanaan Kegiatan/ Hasil \\
\hline a. & Sumber Kegiatan & - \\
\hline b. & $\begin{array}{l}\text { Tanggal } \\
\text { Pelaksanaan }\end{array}$ & 2-12 Oktober 2019 \\
\hline c. & Lokasi/ Tempat & $\begin{array}{l}\text { Ruang kuliah Fakultas Dakwah dan Komunikasi UIN } \\
\text { Walisongo }\end{array}$ \\
\hline $\mathrm{d}$. & Tahapan Kegiatan & $\begin{array}{l}\text { 1. Menentukan waktu pelaksanaan. } \\
\text { 2. Pelaksanaan diskusi oleh mahasiswa } \\
\text { 3. Menerima respon dan mencatat jika ada masukan }\end{array}$ \\
\hline e. & Hasil/ Output & $\begin{array}{l}\text { - Mendapatkan hasil diskusi mahasiswa } \\
\text { - Dokumentasi foto } \\
\text { - } \text { Foto dokumentasi catatan diskusi mahasiswa. }\end{array}$ \\
\hline f. & $\begin{array}{l}\text { Kontribusi / } \\
\text { Manfaat kegiatan } \\
\text { tsb bagi pihak lain } \\
\text { dan terhadap } \\
\text { pencapaian visi misi } \\
\text { organisasi }\end{array}$ & $\begin{array}{l}\text { Memberikan masukan terhadap penulis dalam } \\
\text { pengambilan keputusan berkaitan dengan penguatan } \\
\text { terhadap tata kelola kegiatan pembelajaran. } \\
\text { Kegiatan ini mendukung pencapaian visi dan misi } \\
\text { Fakultas nomor } 1 \text {. Menyelenggarakan pendidikan dan } \\
\text { pengajaran ilmu dakwah dan komunikasi berbasis } \\
\text { kesatuan ilmu pengetahuan untuk menghasilkan lulusan } \\
\text { yang unggul, interdisipliner,kompetitif dan berakhlak al- } \\
\text { karimah. }\end{array}$ \\
\hline g. & $\begin{array}{l}\text { Uraian Kendala } \\
\text { yang Timbul dan } \\
\text { Strategi Mengatasi } \\
\text { Kendala }\end{array}$ & $\begin{array}{l}\text { Pengkondisian mahasiswa agar lebih tertib dalam proses } \\
\text { diskusi }\end{array}$ \\
\hline
\end{tabular}




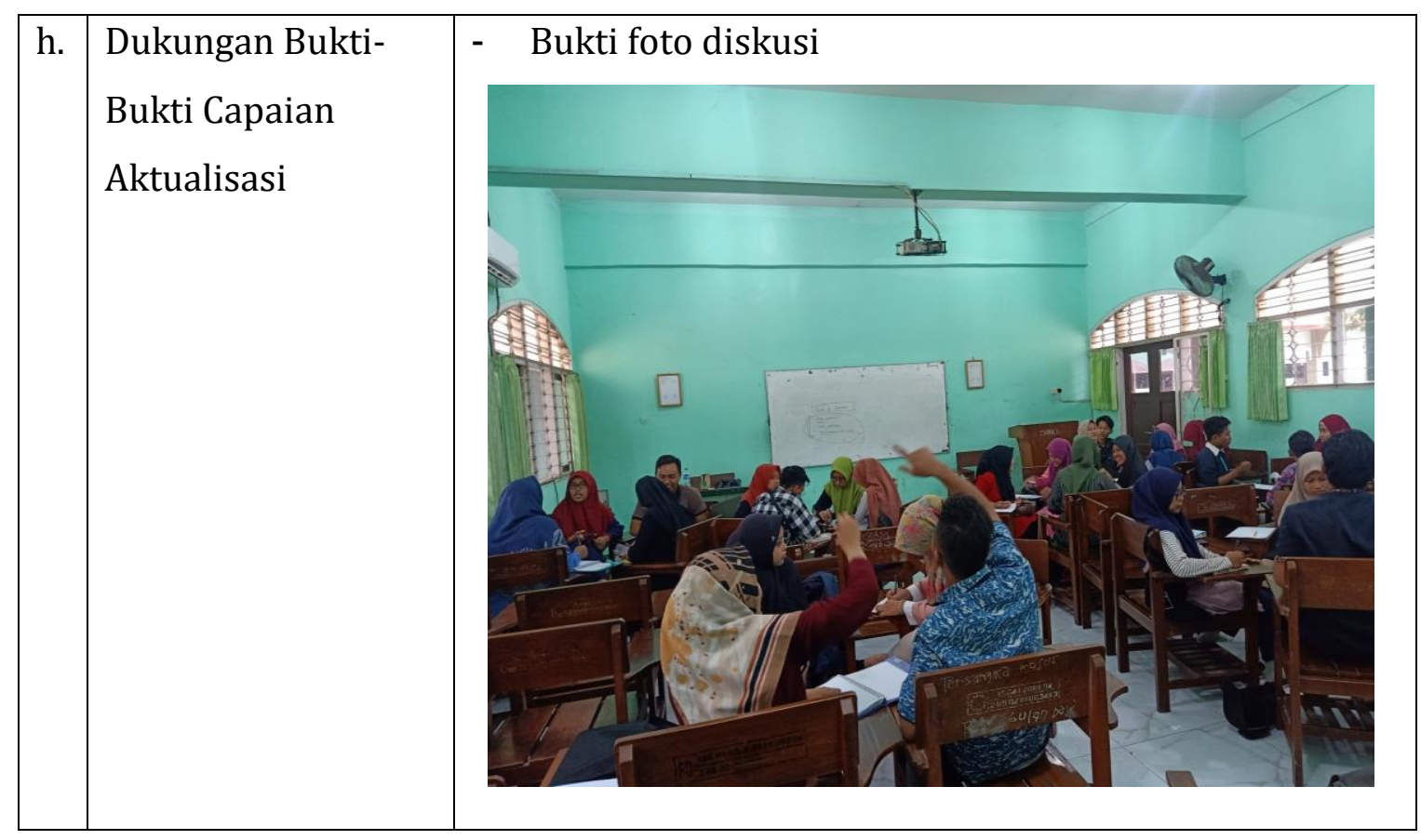

Tabel 3 Uraian Hasil Kegiatan

Penguatan Materi Perkuliahan Sejarah Peradaban Islam

\begin{tabular}{|l|l|l|}
\hline \multicolumn{2}{|c|}{ Rincian Kegiatan } & \multicolumn{1}{c|}{ Pelaksanaan Kegiatan/ Hasil } \\
\hline a. & Sumber Kegiatan & - \\
\hline b. & Tanggal Pelaksanaan & 2-12 Oktober 2019 \\
\hline c. & Lokasi/ Tempat & $\begin{array}{l}\text { Ruang perkuliahan Fakultas Dakwah dan Komunikasi } \\
\text { UIN Walisongo }\end{array}$ \\
\hline d. & Tahapan Kegiatan & $\begin{array}{l}\text { 1. Menentukan waktu pelaksanaan } \\
\text { 2. Pelaksanaan penguatan materi perkuliahan } \\
\text { 3. Menerima respon dan mencatat jika ada masukan }\end{array}$ \\
\hline e. & Hasil/ Output & - Mendapatkan penguatan materi perkuliahan \\
& & - Dokumentasi foto \\
\hline
\end{tabular}




\begin{tabular}{|c|c|c|}
\hline f. & $\begin{array}{l}\text { Kontribusi / Manfaat } \\
\text { kegiatan tsb bagi } \\
\text { pihak lain dan } \\
\text { terhadap pencapaian } \\
\text { visi misi organisasi }\end{array}$ & $\begin{array}{l}\text { Memberikan masukan terhadap penulis dalam } \\
\text { pengambilan keputusan berkaitan dengan penguatan } \\
\text { terhadap tata kelola kegiatan pembelajaran. } \\
\text { Kegiatan ini mendukung pencapaian visi dan misi } \\
\text { Fakultas nomor } 1 \text {. Menyelenggarakan pendidikan dan } \\
\text { pengajaran ilmu dakwah dan komunikasi berbasis } \\
\text { kesatuan ilmu pengetahuan untuk menghasilkan } \\
\text { lulusan yang unggul, interdisipliner,kompetitif dan } \\
\text { berakhlak al-karimah. }\end{array}$ \\
\hline g. & $\begin{array}{l}\text { Uraian Kendala yang } \\
\text { Timbul dan Strategi } \\
\text { Mengatasi Kendala }\end{array}$ & $\begin{array}{l}\text { Koordinasi dengan mahasiswa agar proses } \\
\text { pembelajaran Sejarah Peradaban Islam dengan model } \\
\text { CIRC dapat tercapai maksimal }\end{array}$ \\
\hline h. & $\begin{array}{l}\text { Dukungan Bukti-Bukti } \\
\text { Capaian } \\
\text { Aktualisasi }\end{array}$ & $\begin{array}{l}\text { OSEJARAH } \\
\text { PERADABAN } \\
\text { ISLAM }\end{array}$ \\
\hline
\end{tabular}

\section{SIMPULAN}

Kemampuan mahasiswa terhadap kemampuan membaca pemahaman ditandai dengan: 1) kemampuan mahasiswa menangkap dan memahami isi wacana baik secara tersirat maupun tersurat, 2) kemampuan mahasiswa dalam menjawab pertanyaan sesuai isi wacana, 3) kemampuan mahasiswa meringkas isi wacana dengan menemukan ide pokok terhadap paragraf terkait, 4) kemampuan mahasiswa menyimpulkan dan menceritakan kembali isi wacana dengan kalimat sendiri dan dengan bahasa yang runtut. 
Berdasarkan hasil temuan penelitian dan pembahasan yang dilaksanakan, dapat diambil kesimpulan yaitu sebagai berikut:

1) Penerapan metode CIRC meningkatkan kemampuan membaca pemahaman mahasiswa terhadap mata kuliah Sejarah Peradaban Islam di dalam kelas.

2) Peningkatan kemampuan membaca pemahaman mahasiswa serta proses diskusi dapat dilihat dari nilai hasil Ujian kemampuan membaca pemahaman mahasiswa.

\section{DAFTAR PUSTAKA}

Abidin, Yunus. Pembelajaran Membaca Berbasis Karakter. Bandung: Refika Aditama. 2016

Abidin, Yunus. Model Penilaian Otentik dalam Pembelajaran Membaca Pemahaman Berorientasi Pendidikan Karakter. Jurnal Pendidikan Karakter. (2). HIm. 173175. 2012

Anwar. Pendidikan Kecakapan Hidup (Life Skills Education). Bandung: Alfabeta, 2006.

Djamarah, Syaiful Bahri. Psikologi Belajar. Jakarta: PT Rineka Cipta, 2005.

Maunah, binti. Metodologi Pengajaran Agama Islam. Yogyakarta: sukses offset, 2009.

Slavin, Robert E. Cooperative Learning: Theory, Research and Practice, terj: Nurulita Yusron. Bandung: Nusa Media, 2008.

Somadayo. Metode dan Teknik Pembelajaran Membaca. Yogyakarta: Graha Ilmu. 2011 Syah, Muhibbin, Psikologi Pendidikan Suatu Pendekatan Baru,. Bandung: PT Remaja Rosda Karya, 2004.

Tarigan. Membaca Sebagai Suatu Keterampilan Berbahasa. Bandung: Angkasa. 2008 Zaini, hisyam, bermawy, and sekar ayu aryani. Strategi pembelajaran. IV. Yogyakarta: ctsd, 2007. 